\title{
Invasion of the cavernous sinus space in pituitary adenomas: endoscopic verification and its correlation with an MRI-based classification
}

\author{
Alexander S. G. Micko, MD, ${ }^{1}$ Adelheid Wöhrer, MD, PhD, ${ }^{2}$ Stefan Wolfsberger, MD, ${ }^{1}$ \\ and Engelbert Knosp, MD' \\ ${ }^{1}$ Department of Neurosurgery and ${ }^{2}$ nstitute of Neurology, Medical University of Vienna, Austria
}

\begin{abstract}
OBJECT An important prognostic factor for the surgical outcome and recurrence of a pituitary adenoma is its invasiveness into parasellar tissue, particularly into the space of the cavernous sinus (CS). The aims of this study were to reevaluate the existing parasellar classifications using an endoscopic technique and to evaluate the clinical and radiological outcomes associated with each grade.
\end{abstract}

METHODS The authors investigated 137 pituitary macroadenomas classified radiologically at least on one side as Grade 1 or higher (parasellar extension) and correlated the surgical findings using an endoscopic technique, with special reference to the invasiveness of the tumor into the CS. In each case, postoperative MRI was performed to evaluate the gross-total resection (GTR) rate and the rate of endocrinological remission (ER) in functioning adenomas.

RESULTS The authors found a $16 \%$ rate of CS invasion during surgery for these macroadenomas. Adenomas radiologically classified as Grade 1 were found to be invasive in $1.5 \%$, and the GTR/ER rate was $83 \% / 88 \%$. For Grade 2 adenomas, the rate of invasion was $9.9 \%$, and the GTR/ER rate was $71 \% / 60 \%$. For Grade 3 adenomas, the rate of invasion was $37.9 \%$, and the GTR/ER rate was $75 \% / 33 \%$. When the superior compartment of the CS (Grade $3 \mathrm{~A}$ ) was involved, the authors found a rate of invasion that was lower $(p<0.001)$ than that when the inferior compartment was involved (Grade 3B). The rate of invasion in Grade 3A adenomas was $26.5 \%$ with a GTR/ER rate of $85 \% / 67 \%$, whereas for Grade $3 \mathrm{~B}$ adenomas, the rate of surgically observed invasion was $70.6 \%$ with a GTR/ER rate of $64 \% / 0 \%$. All of the Grade 4 adenomas were invasive, and the GTR/ER rate was $0 \%$.

A comparison of microscopic and endoscopic techniques revealed no difference in adenomas with Grade 1 or 4 parasellar extension. In Grade 2 adenomas, however, the CS was found by the endoscopic technique to be invaded in $9.9 \%$ and by microscopic evaluation to be invaded in $88 \%(p<0.001)$; in Grade 3 adenomas, the difference was $37.9 \%$ versus $86 \%$, respectively $(p=0.002)$. Grade 4 adenomas had a statistically significant lower rate of GTR than those of all the other grades. In case of ER only, Grade 1 adenomas had a statistically significant higher rate of remission than did Grade 3B and Grade 4 adenomas.

CONCLUSIONS The proposed classification proved that with increasing grades, the likelihood of surgically observed invasion rises and the chance of GTR and ER decreases. The direct endoscopic view confirmed the low rate of invasion of Grade 1 adenomas but showed significantly lower rates of invasion in Grade 2 and 3 adenomas than those previously found using the microscopic technique. In cases in which the intracavernous internal carotid artery was encased (Grade 4), all the adenomas were invasive and the GTR/ER rate was $0 \% / 0 \%$. The authors suggest the addition of Grades $3 \mathrm{~A}$ and $3 \mathrm{~B}$ to distinguish the strikingly different outcomes of adenomas invading the superior CS compartments and those invading the inferior CS compartments.

http://thejns.org/doi/abs/10.3171/2014.12.JNS141083

KEY WORDS classification; endoscopic view; invasive pituitary adenoma; parasellar; pituitary surgery

ABBREVIATIONS CS = cavernous sinus; ER = endocrinological remission; GTR = gross-total resection; ICA = internal carotid artery.

SUBMITTED May 22, 2014. ACCEPTED December 2, 2014.

INCLUDE WHEN CITING Published online February 6, 2015; DOI: 10.3171/2014.12.JNS141083.

DISCLOSURE The authors report no conflict of interest concerning the materials or methods used in this study or the findings specified in this paper. 
$\mathrm{T}$ HE chances of complete resection and endocrinological remission (ER) of pituitary adenomas are reported to depend on their growth rate, size, ${ }^{8,51}$ histological subtype, 3,46 and invasiveness into the surrounding structures. Special attention has been drawn to the endosteum of the sellar floor, the rate of histological invasion into which has been reported to be as high as 46\%-85\%. ${ }^{52,62}$ Overt parasellar invasion into cavernous sinus (CS) structures is found intraoperatively in $6 \%-10 \%{ }^{1,20}$ of cases and is the most important reason for incomplete resection and the decrease in cure rates from $78 \%-92 \%$ (in cases without parasellar invasion) to $20 \%-$ $52 \% .16,20,21,24,36,39,62,64$

Because of the close relationship of the internal carotid arteries (ICAs), histological specimens of the medial wall are not routinely available, ${ }^{54,65,77}$ so surgical observations ${ }^{59}$ and/or radiological signs of invasion ${ }^{14}$ are still the most important methods of detection.

Previous studies on the prognosis of invasiveness defined by preoperative MRI based the true intraoperative status of invasiveness on observations through an operating microscope. ${ }^{44}$

Because of the ease of application and its practical relevance, a classification proposed previously ${ }^{44}$ has become a grading system for surgeons and radiologists. ${ }^{13,19,26,40 \text {, }}$ $41,56,67,73$ It is based on coronal sections of T1-weighted contrast-enhanced MRI scans, in which the circular cuts of the ICAs serve as easily detectable radiological landmarks for medial, center, and lateral tangents. ${ }^{14}$

At the time that these studies were published, the microscopic technique was standard for transsphenoidal surgery, although drawbacks included a limited lateral view toward the medial wall and problems removing tumor tissue compressing or invading the compartments of the space of the CS and the ICA itself. The application of endoscopes in transsphenoidal surgery in the 1990s changed this situation, because the lenses provided a wider field of view. 11,15,36,39,60 This wider view enables the surgeon to inspect the medial wall of the CS directly and therefore to pass a more reliable judgment regarding parasellar invasiveness.

The aim of this study was to investigate direct endoscopic visualization of the medial wall of the CS to assess the invasiveness of pituitary adenomas into the CS space and reassess the established classification, which was originally based on observations from a microscopic view. ${ }^{44}$

\section{Methods}

This study was approved by the ethical review committee at the Medical University of Vienna and was performed in accordance with the principles of the Declaration of Helsinki. ${ }^{69}$

All data were culled from a prospectively acquired database of patients with sella turcica pathology who underwent surgery at the Medical University of Vienna Department of Neurosurgery.

We evaluated a consecutive series of 137 patients with pituitary macroadenomas with parasellar extension. All the surgeries were performed between 2003 and 2013 via a pure endoscopic transnasal transsphenoidal approach.
Subsequent surgeries for pituitary adenomas and other pathologies inside the sella turcica were excluded from this study. For patient and tumor characteristics, see Table 1.

Magnetic resonance images were acquired in each patient using standard 1.5- or 3.0-T scanners and included T1-weighted coronal slices with and without contrast enhancement preoperatively and postoperatively; T2weighted images were added in most cases. Our MRI protocol also includes MR angiography as a part of preoperative navigation planning.

\section{Parasellar Extension on MRI (Grading System)}

To compare radiological characteristics of CS involvement with our surgical findings, we used a previously published grading system. ${ }^{44}$ This grading system classifies the parasellar extension of pituitary adenomas on coronal MRI. Three lines connecting the cross-section of the intracavernous and supracavernous ICAs distinguish 4 grades of parasellar adenoma extension: a medial tangent, a line through the cross-sectional centers, and a lateral tangent (Fig. 1). Using this grading system, the parasellar extension of all 137 pituitary adenomas on either side into 274 CSs was retrospectively assessed by A.M., who was blinded to the results of the intraoperative findings. In each case, the parasellar extension was at least Grade 1 on one side, which means that the tumor's growth extended beyond the medial tangent.

\section{Surgical Technique-Observed Invasion Into the Space of the CS}

We usually start with the wider nasal cavity, which facilitates the approach to the ostium.

Depending on the size and the parasellar extension of the adenoma, a mononostril or binostril approach was taken. In each case with encasement of the ICA (Grade 4), the turbinate ipsilateral to the lesion was dissected, and a partial or complete ethmoidectomy was performed to reach the anterior ICA siphon knee adequately.

The sella was approached through the nasal cavity ipsilateral to the side of parasellar tumor extension of higher grade. We used endoscopic equipment with a 4-mm diameter, an 18-cm length, and 0-, 30-, and 45-degree optics (Hopkins optics; Karl Storz $\mathrm{GmbH}$ ) with a cleaning system. This tool became an important component of this technique.

After opening the bony sellar floor, from one side of the CS to the other side, a quadrangular piece of basal sellar dura was routinely excised and sent for histological assessment of adenoma invasion. If the adenoma invaded the dura diffusely, bone and/or mucosal specimens from the dura itself for histological analysis are sometimes missing. Adenoma resection was commenced after broadly opening the sella floor. Depending on the size and consistency of the tumor, the center of the endosellar part was removed to develop an extracapsular dissection. Whenever possible, the suprasellar component was left unremoved until the parasellar tumor was resected. After tumor debulking, extracapsular dissection was continued with special attention to the parasellar tumor extension. ${ }^{11}$ This is usually the time to apply 30- and/or 45-degree angled endoscopes and 
TABLE 1. Patient and tumor characteristics

\begin{tabular}{|c|c|}
\hline Characteristic & Value \\
\hline Sex, male/female & $1: 0.85$ \\
\hline Age (median \pm SD [range]) (yrs) & $52.5 \pm 15(7-80)$ \\
\hline \multicolumn{2}{|l|}{ Localization } \\
\hline Subsellar & 19 \\
\hline \multicolumn{2}{|c|}{$\begin{array}{l}\text { Suprasellar extension (suprasellar grading*) } \\
\text { (no. [\%]) }\end{array}$} \\
\hline Grade 1 & $9(7)$ \\
\hline Grade 2 & $3(2)$ \\
\hline Grade A & $36(26)$ \\
\hline Grade B & $57(42)$ \\
\hline Grade C & $24(17)$ \\
\hline Grade D & $8(6)$ \\
\hline \multicolumn{2}{|c|}{ Parasellar grading $\dagger$ (no. on rt side, no. on It side) } \\
\hline Grade 0 & 29,29 \\
\hline Grade 1 & 31,37 \\
\hline Grade 2 & 38,33 \\
\hline Grade 3A & 22,27 \\
\hline Grade 3B & 12,5 \\
\hline Grade 4 & 5,6 \\
\hline \multicolumn{2}{|l|}{ Size (no.) } \\
\hline Microadenoma & 0 \\
\hline Macroadenoma & 137 \\
\hline Diameter (median \pm SD [range]) $(\mathrm{mm})$ & $27 \pm 10(11-70)$ \\
\hline $11-20$ mm (no. [\%]) & $42(31)$ \\
\hline 21-30 mm (no. [\%]) & $59(43)$ \\
\hline $31-40$ mm (no. [\%]) & $30(22)$ \\
\hline$>40$ mm (“giant”) (no. [\%]) & $6(4)$ \\
\hline \multicolumn{2}{|l|}{ Hormonal subtype } \\
\hline Inactive (no.) & 108 \\
\hline Null-cell adenoma & 61 \\
\hline Gonadotropinoma & 35 \\
\hline Silent ACTH & 5 \\
\hline Plurihormonal & 7 \\
\hline Active (no.) & 29 \\
\hline PRL cell adenoma & 14 \\
\hline GH cell adenoma & 14 \\
\hline ACTH cell adenoma & 1 \\
\hline
\end{tabular}

$\mathrm{ACTH}=$ adrenocorticotropic hormone; $\mathrm{GH}=$ growth hormone; $\mathrm{PRL}=$ prolactin .

* According to Hardy and Vezina ${ }^{30}$ and Hardy and Wigser. ${ }^{31}$

$\dagger$ According to Knosp et al. ${ }^{44}$

curved or angulated suction devices. Removal of the tumor from the CS space was performed with blunt curettes only. We avoided scissors and sharp instruments unless the ICA was clearly detected. Bleeding from the CS was controlled by hemostyptics and fibrin glue. In a close-up view, the integrity of the medial CS wall was assessed visually. Invasiveness of the adenoma tissue was judged by the performing neurosurgeons (E.K. and S.W.), who documented their impressions in the operating report.

If the medial wall was smooth and intact after tumor removal, we deemed invasion to be absent. If the medial wall was not detectable and trabeculae, intracavernous ligaments, or sympathetic nerve fibers were visible and surrounded by the tumor, we deemed invasion to be present. We also considered an invasion present if the adventitia of the intracavernous ICA was directly visible.

Only after inspection of the medial wall on both sides was the suprasellar tumor part dissected and removed.

\section{Follow-Up}

Each patient in this study received postoperative MRI (at 1.5 or $3.0 \mathrm{~T}$ ) with and without contrast enhancement. MRI, performed 3 months postoperatively, determined gross-total resection (GTR), and yearly follow-up was performed. We used the most recent consensus statements ${ }^{5,6}$, 25,53 to define ER.

\section{Histologically Observed Invasiveness}

We obtained basal sellar dura samples of the anterior sellar wall for histological examination. When explicit invasion was observed or suspected, we tried to obtain this part of the endosteum for histological examination. The reasons for not including the results of the remaining specimens were severe coagulation artifacts, fragments too small for a relevant decision to be made, and/or absent endosteum resulting from tumor invasion.

Pituitary adenoma tissue samples were taken not only for immunohistological staining but also for analysis of MIB-1, which is an antibody against Ki-67, a protein expressed in proliferating cells. ${ }^{66}$

\section{Statistical Analysis}

The radiologically determined grade of parasellar tumor extension according to preoperative MRI was evaluated with the reviewer blinded to the surgical results. The rate of tumor invasiveness was then calculated for each radiologically determined grade of parasellar extension. The data are presented as means and ranges for continuous variables and as frequencies for categorical variables.

For the comparison of our results from endoscopic assessments of invasiveness with our previous data from assessments with an operating microscope ${ }^{44}$ we used the chi-square test. For comparison of the intraoperative status of invasiveness and the cell-proliferation (MIB-1) index, the independent-samples t-test was used.

A $p$ value of $<0.05$ was considered significant. For statistical analyses, SPSS version 20.0 software (SPSS, Inc.) was used.

\section{Results}

\section{Parasellar Extension on MRI}

On preoperative coronal MRI, the parasellar extension into $274 \mathrm{CSs}$ was Grade 0 in 58 (21\%), Grade 1 in 68 cases $(25 \%)$, Grade 2 in 71 (26\%), Grade 3 (into the superior ICA compartment [further named Grade 3A]) in 49 (18\%), Grade 3 (into the inferior ICA compartment [further named Grade 3B]) in 17 (6\%), and Grade 4 in 11 (4\%) (Table 1). 

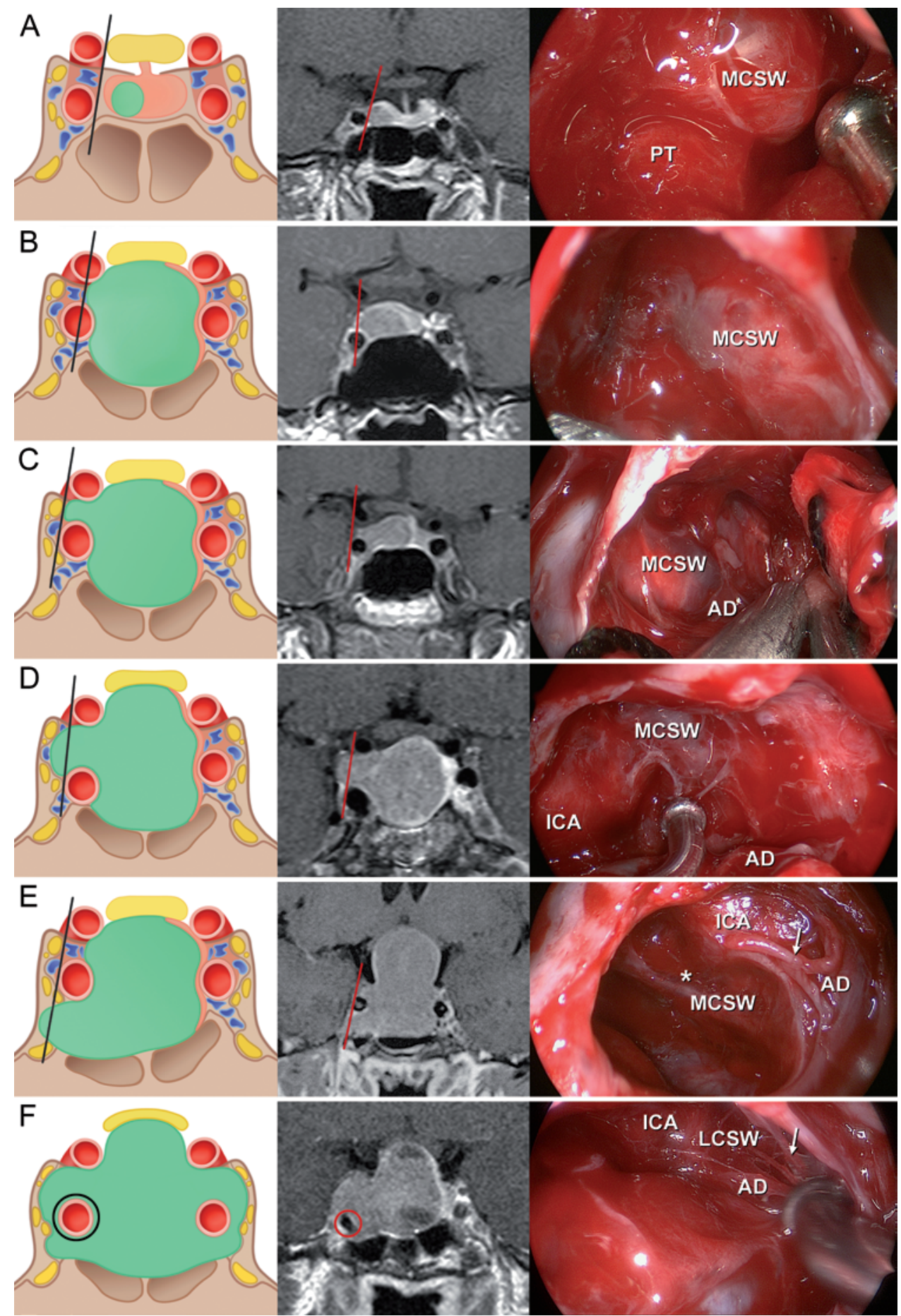

FIG. 1. Graphic schemes (left), coronal MR images (center), and endoscopic views (right). A: Grade 0: the adenoma does not encroach on the CS space. Thus, the tangent of the medial aspects of the intracavernous and supracavernous ICAs is not passed. ${ }^{44}$ B: Grade 1: the medial tangent is passed, but the extension does not go beyond a line drawn between the crosssectional centers of the intracavernous and supracavernous ICAs (the intercarotid line). ${ }^{44}$ C: Grade 2: the tumor extends beyond the intercarotid line but not past the tangent on the lateral aspects of the intracavernous and supracavernous ICAs. ${ }^{44}$ D: Grade $3 \mathrm{~A}$ : the tumor extends lateral to the lateral tangent of the intracavernous and supracavernous ICAs into the superior CS compartment. ${ }^{44} \mathrm{E}$ : Grade 3B: the tumor extends lateral to the lateral tangent of the intracavernous and supracavernous ICAs into the inferior CS compartment. F: Grade 4: there is total encasement of the intracavernous carotid artery ${ }^{44} \mathrm{AD}=$ adenoma; $\mathrm{LCSW}=$ lateral CS wall (seen after removing the medial CS wall); MCSW = medial CS wall; PT = pituitary gland. The asterisk indicates an invaded medial CS wall, and arrows indicate trabeculae. Copyright Engelbert Knosp. Published with permission. 


\section{Endoscopic Assessment of Invasiveness Into the CS Space}

A comparison with our previously published data (Table 2) derived from a microscopic assessment of invasiveness $^{44}$ revealed no differences in the invasiveness of Grade 0,1 , and 4 adenomas.

None of the Grade 0 and all of the Grade 4 adenomas were invasive according to intraoperative observations.

In Grades 2 and 3, however, direct endoscopic visualization of the medial CS structures revealed a lower incidence of invasiveness by endoscopic than by microscopic visualization (9.9\% vs $88 \%$ for Grade 2 and $37.9 \%$ vs $86 \%$ for Grade 3, respectively). These differences were significant $(\mathrm{p}<0.001$ and $\mathrm{p}=0.002$, respectively).

Grade 3 adenomas that extended beyond the lateral tangent of the ICAs into the inferior CS compartment were significantly more commonly invasive than those that extended into the superior compartment $(70.6 \%$ vs $26.5 \%$, respectively; $\mathrm{p}<0.001)$.

\section{Surgically Observed Invasiveness}

In total, signs of invasion were observed in 44 (16.1\%) of the 274 CSs. No adenomas with parasellar extension Grade 0 were found intraoperatively to be invasive. Adenomas with parasellar extension Grades 1, 2, and 3 were found to be invasive in $1.5 \%, 9.9 \%$, and $37.9 \%$ of the cases, respectively. Grade 3B adenomas, which extended beyond the lateral tangent of the ICAs into the inferior CS compartment, were significantly more commonly invasive than those that extended into the superior compartment (termed Grade 3A adenomas) (70.6\% vs $26.5 \%$, respectively; $\mathrm{p}<0.001)$.

In the analysis of the side of invasion, we found that the inferior compartment was affected more frequently than the superior compartment. Therefore, because of the significant difference, we decided to subdivide Grade 3 into Grade 3A (superior CS compartment) and Grade 3B (inferior CS compartment).

All adenomas with total encasement of the ICA (Grade 4) were confirmed intraoperatively to be invasive. In terms of the correlation between the dural and CS invasiveness of these macroadenomas, we did not find a statistically significant difference and therefore no correlation for the groups as a whole or for the different grades.

\section{Follow-Up}

The MRI and endocrinological follow-up period ranged

TABLE 2. Adenoma invasiveness into the CS space (left and right sides) according to grade and technique

\begin{tabular}{ccccccc}
\hline & $\begin{array}{c}\text { Invasiveness Observed } \\
\text { Endoscopically }\end{array}$ & & \multicolumn{2}{c}{$\begin{array}{c}\text { Invasiveness Observed } \\
\text { Microscopically }\end{array}$} & \\
\cline { 2 - 3 } Gradennnnnnn & No./Total No. & $\%$ & & No./Total No. & $\%$ & p Value \\
\hline 0 & $0 / 58$ & 0 & & $0 / 11$ & 0 & NS \\
\hline 1 & $1 / 68$ & 1.5 & & $0 / 8$ & 0 & NS \\
\hline 2 & $7 / 71$ & 9.9 & & $7 / 8$ & 88 & $<0.001$ \\
\hline 3 & $25 / 66$ & 37.9 & & $12 / 14$ & 86 & 0.002 \\
\hline 4 & $11 / 11$ & 100 & & $9 / 9$ & 100 & NS \\
\hline
\end{tabular}

NS = not significant. from 3 months to 2 years. GTR, as shown on postoperative MRI, was achieved in $83 \%, 71 \%, 85 \%$, and $64 \%$ of Grade 1, 2, 3A, and 3B adenomas, respectively. All cases of parasellar extension Grade 4 showed tumor remnants on follow-up MRI. Residuals were usually found as expected in the most difficult-to-access space lateral to the intracavernous ICA.

Endocrinological remission was achieved in $88 \%, 60 \%$, $67 \%, 0 \%$, and $0 \%$ of Grade $1,2,3 \mathrm{~A}, 3 \mathrm{~B}$, and 4 adenomas, respectively. Grade 4 adenomas had a statistically significant lower rate of GTR than did all the other grades. In cases of ER, only Grade 1 adenomas had a statistically significant higher rate of remission than Grade 3B and Grade 4 adenomas (Table 3 ).

\section{Histologically Observed Invasiveness}

In 96 of 137 cases, we obtained samples of the basal sellar dura of the anterior sellar wall for histological examination. Histological signs of basal endosteum invasion were evaluated in 41 (42.7\%) of the 96 cases studied.

The MIB-1 analysis of CS-invasive (MIB-1 mean 3.24) and -noninvasive (MIB-1 mean 2.17) adenomas revealed a strong tendency, but no statistically significant correlation, to higher MIB-1 in invasive cases $(\mathrm{p}=0.075)$.

\section{Discussion Invasiveness}

Larger tumor size and growth are the prime causes for incomplete tumor resection and failed ER of pituitary adenomas. ${ }^{16,20,21,36,39,62,64}$ In contrast to mere tumor extension with lateral displacement of CS structures, the term "invasiveness" is reserved for pituitary adenomas for which infiltrative growth into surrounding structures can be observed during surgery. This invasion by pituitary adenomas was described beautifully by Jefferson ${ }^{35}$ in 1955, when he identified 14 cases of local spread/infiltration into the CS and the sphenoid sinus, most of which had histological signs of anaplastic and undifferentiated cells. Jefferson reported surgical observations first and then later radiological observations, which resulted in the first radiological classification of pituitary adenomas (based on plain radiographs of the sella turcica). ${ }^{29,31}$ Hardy and Vezina ${ }^{30}$ distinguished noninvasive grades (enclosed) from invasive grades. Later, with CT scans, the suprasellar component was visible directly, which led to adoption of their classification (stages A-D). With coronal CT scans of the sella, the anatomy and pathology of the parasellar region came into focus. ${ }^{7}$ The breakthrough for imaging the CS was MRI technology, which inspired surgeons in this field. ${ }^{18,44,58,61}$ In coronary sections of the sella, the adenomas and ICAs were easily detectable within the CS space.

TABLE 3. Parasellar invasion compared with GTR/ER and MIB-1

\begin{tabular}{ccccc}
\hline Grade & Parasellar Invasiveness (\%) & GTR (\%) & ER (\%) & MIB-1 (\%) \\
\hline 1 & 1.5 & 83 & 88 & 2.5 \\
\hline 2 & 9.9 & 71 & 60 & 2.8 \\
\hline 3A & 26.5 & 85 & 67 & 2.5 \\
\hline 3B & 70.6 & 64 & 0 & 2.3 \\
\hline 4 & 100 & 0 & 0 & 4.1 \\
\hline
\end{tabular}


A radiological classification of the parasellar growth of adenomas had been proposed previously and applied widely. ${ }^{13,21,27,44,45,63,78}$ In the higher grades of the classification scale, invasion of the CS space is observed more often and the cure rate decreases inversely.

The judgment of adenoma invasion into the CS space during microscopic transsphenoidal surgery had considerable drawbacks because of the limited area of visualization of the medial wall.

Our study was performed using an endoscopic technique, which made direct visual inspection of the complete medial CS wall possible. Improved illumination, high magnification, and direct close-up views "around the corner" using angled endoscopes offer significant advantages over microscopic transsphenoidal surgery for detecting adenoma invasion of the CS space. $9,10,12,22,27,34,36-38,49,57$

For Grade 1 and 4 adenomas (with encasement of the ICA), there were no differences between microscopic and endoscopic judgments of invasiveness.

It is remarkable that we have succeeded in demonstrating a significantly lower rate of invasiveness in Grade 2 and 3 adenomas than in those in our original study. The analysis of Grade 3 adenomas revealed significant diversity within the grade. Therefore, the individual cases were further investigated. It became apparent that Grade 3 could be subclassified because of the tumors' extension into either the superior CS compartment or the inferior CS compartment. We therefore subdivided Grade 3 into Grades 3A and 3B. The growth of tumor tissue into the inferior compartment led significantly more often to an invasion of the medial wall of the CS. These results are in concordance with those in previous reports, especially in growth hormone-producing adenomas. ${ }^{4,28,78}$

With each increasing grade, we found not only a higher rate of invasion but also lower rates of GTR and ER in the follow-up (Table 3).

The histopathological assessment of adenoma invasion into the basal sellar dura adds an additional index for an overall picture of the biological behavior of these tumors. Histological invasiveness of dural structures has been reported to be as common as $46 \%-85 \%$ (42.7\% in our present series)..$^{52,62}$

Despite the endoscopic technique, a direct biopsy of the connective tissue of the medial CS wall is not feasible in routine clinical practice because of the danger of injuring neurovascular structures. Resection of the medial wall should be performed by very experienced surgeons only. ${ }^{50}$

The only direct sign of adenoma invasiveness on preoperative MRI is interruption of the medial CS wall. Using the hypothesis that high-field MR scanners can visualize such discontinuation, we were able to directly demonstrate adenoma invasiveness with high-resolution T2-weighted coronal MRI with high sensitivity and specificity. ${ }^{70}$ In the clinical setting, however, high-field scanners have failed to routinely result in such high anatomical resolution, possibly because of the susceptibility to artifacts in the region of the skull base and a lack of dedicated imaging sequences. Therefore, to date, the preoperative assessment of CS invasion is still based on indirect radiological signs.

The medial wall of the CS was the focus of this study in cases without adenoma invasion. It is a shiny thin wall that, according to our experience with anatomical dissections, is a well-defined, dissectible membrane adjacent to the lateral part of the pituitary gland. This membrane is fragile but unfenestrated, contrary to reports from Yasuda et al ${ }^{74-76}$ Only the inferior hypophyseal artery and the pituitary veins pass through the medial CS wall. Therefore, holes in and/or disruptions of the medial wall of the CS observed during surgery are, according to our experience, results of tumor invasion (when the tumor is found within the space of the CS).

Because it provides direct visualization of the medial wall, the endoscopic technique is the best available method for distinguishing between invasion and compression. Histopathological analysis of the medial wall itself remains the gold standard of diagnosis, but routine biopsies seem to be too dangerous.

\section{MIB-1 Index}

Following the revision of the 2004 WHO classification, diagnostic criteria for an atypical adenoma include excessive p53 immunoreactivity, an MIB-1 proliferative index of $>3 \%$, and increased mitotic activity. ${ }^{17}$ We agree with the concept of atypical adenomas, higher proliferation rates, and invasive growth. We did not correlate our data with $\mathrm{p} 53$ expression, because it does not seem to be of pathogenetic significance in pituitary tumors. $23,32,33,45,48,55,63$ Tumor proliferation markers, such as the Ki-67-targeted MIB-1 labeling index, were observed by others ${ }^{47}$ and our group ${ }^{42,43,68,71,72}$ to correlate with more aggressive biological pituitary adenoma behavior, such as an increased growth rate and invasive growth. These recent data support our previous results, although MIB-1 did not achieve significance between the grades, most likely because all of the included tumors were macroadenomas.

\section{Risk of Surgery Within the CS}

Because of rupture of the ICAs and damage to cranial nerves III-VI, CS surgery had been avoided previously. Only after the pioneering works of Parkinson, ${ }^{58}$ Dolenc, ${ }^{18}$ and others has surgery of the CS (intradural or transcranial) become possible. Using the transsphenoidal route, the risk of ICA injury is currently reported to be $0.5 \%-1.6 \% .^{2}$

Although we tried to remove as much tumor from the CS space as possible, we caused no ICA injuries during pure endoscopic surgery. We never used sharp instruments such as forceps, scissors, or sharp spoons and inflicted no lacerations on the major vessels or the ICAs. With these precautions, no higher morbidity or mortality rates were encountered. Furthermore, there was no excessive venous bleeding to force the surgeon to stop the surgery or to apply a blood replacement therapy, and no newly diagnosed cranial nerve deficits were observed postoperatively.

\section{Conclusions}

Our study shows that at each higher grade, the likelihood of surgically observed adenoma invasion rises and the chance of GTR/ER decreases. Direct endoscopic visualization is the crucial difference that provides a decisive advantage over the microscopic technique. The direct endoscopic view confirmed a low rate of invasion in Grade 
1 adenomas and showed significantly lower rates of invasion in Grades 2 and 3 than previously found using the microscopic technique. In cases in which the intracavernous ICA was total encased (Grade 4), all the adenomas were invasive, and the GTR/ER rate was $0 \% / 0 \%$. We suggest adding Grades 3A and 3B to the existing parasellar classification to distinguish the strikingly different outcomes of adenomas invading the superior CS compartments and those invading the inferior CS compartments.

\section{Acknowledgment}

We thank Brigitte Dobsak for drawing the illustrations.

\section{References}

1. Ahmadi J, North CM, Segall HD, Zee CS, Weiss MH: Cavernous sinus invasion by pituitary adenomas. AJR Am J Roentgenol 146:257-262, 1986

2. Ammirati M, Wei L, Ciric I: Short-term outcome of endoscopic versus microscopic pituitary adenoma surgery: a systematic review and meta-analysis. J Neurol Neurosurg Psychiatry 84:843-849, 2013

3. Asa SL, Ezzat S: The cytogenesis and pathogenesis of pituitary adenomas. Endocr Rev 19:798-827, 1998

4. Bakhtiar Y, Hanaya R, Tokimura H, Hirano H, Oyoshi T, Fujio $\mathrm{S}$, et al: Geometric survey on magnetic resonance imaging of growth hormone producing pituitary adenoma. Pituitary 17:142-149, 2014

5. Beck-Peccoz P, Lania A, Beckers A, Chatterjee K, Wemeau JL: 2013 European thyroid association guidelines for the diagnosis and treatment of thyrotropin-secreting pituitary tumors. Eur Thyroid J 2:76-82, 2013

6. Biller BM, Grossman AB, Stewart PM, Melmed S, Bertagna $\mathrm{X}$, Bertherat J, et al: Treatment of adrenocorticotropin-dependent Cushing's syndrome: a consensus statement. J Clin Endocrinol Metab 93:2454-2462, 2008

7. Bonneville JF, Cattin F, Gorczyca W, Hardy J: Pituitary microadenomas: early enhancement with dynamic CT-implications of arterial blood supply and potential importance. Radiology 187:857-861, 1993

8. Brochier S, Galland F, Kujas M, Parker F, Gaillard S, Raftopoulos C, et al: Factors predicting relapse of nonfunctioning pituitary macroadenomas after neurosurgery: a study of 142 patients. Eur J Endocrinol 163:193-200, 2010

9. Cappabianca P, Cavallo LM, Colao A, de Divitiis E: Surgical complications associated with the endoscopic endonasal transsphenoidal approach for pituitary adenomas. J Neurosurg 97:293-298, 2002

10. Cappabianca P, Cavallo LM, Colao A, Del Basso De Caro M, Esposito F, Cirillo S, et al: Endoscopic endonasal transsphenoidal approach: outcome analysis of 100 consecutive procedures. Minim Invasive Neurosurg 45:193-200, 2002

11. Cappabianca P, Cavallo LM, de Divitiis E: Endoscopic endonasal transsphenoidal surgery. Neurosurgery 55:933-941, 2004

12. Cappabianca P, Cavallo LM, Esposito F, Valente V, De Divitiis E: Sellar repair in endoscopic endonasal transsphenoidal surgery: results of 170 cases. Neurosurgery 51:13651372,2002

13. Ceylan S, Koc K, Anik I: Endoscopic endonasal transsphenoidal approach for pituitary adenomas invading the cavernous sinus. J Neurosurg 112:99-107, 2010 (Erratum in J Neurosurg 112:210, 2010)

14. Cottier JP, Destrieux C, Brunereau L, Bertrand P, Moreau L, Jan M, et al: Cavernous sinus invasion by pituitary adenoma: MR imaging. Radiology 215:463-469, 2000
15. de Divitiis E, Cappabianca P: Endoscopic endonasal transsphenoidal surgery. Adv Tech Stand Neurosurg 27:137-177, 2002

16. Dehdashti AR, Ganna A, Karabatsou K, Gentili F: Pure endoscopic endonasal approach for pituitary adenomas: early surgical results in 200 patients and comparison with previous microsurgical series. Neurosurgery 62:1006-1017, 2008

17. DeLellis RA (ed): Pathology and Genetics of Tumours of Endocrine Organs. World Health Organization Classification of Tumours. Lyon: IARC Press, 2004, Vol 8, pp 9-15

18. Dolenc VV (ed): Anatomy and Surgery of the Cavernous Sinus. Vienna: Springer-Verlag, 1989

19. Enseñat J, Ortega A, Topcewski T, Vilalta J, Obiols G, Mesa $\mathrm{J}$, et al: [Predictive value of the Knosp classification in grading the surgical resection of invasive pituitary macroadenomas. A prospective study of 23 cases.] Neurocirugia (Astur) 17:519-526, 2006 (Span)

20. Fahlbusch R, Buchfelder M: Transsphenoidal surgery of parasellar pituitary adenomas. Acta Neurochir (Wien) 92: 93-99, 1988

21. Frank G, Pasquini E: Endoscopic endonasal cavernous sinus surgery, with special reference to pituitary adenomas. Front Horm Res 34:64-82, 2006

22. Gamea A, Fathi M, el-Guindy A: The use of the rigid endoscope in trans-sphenoidal pituitary surgery. J Laryngol Otol 108:19-22, 1994

23. Gejman R, Swearingen B, Hedley-Whyte ET: Role of Ki-67 proliferation index and p53 expression in predicting progression of pituitary adenomas. Hum Pathol 39:758-766, 2008

24. Giovanelli M, Losa M, Mortini P: Surgical therapy of pituitary adenomas. Metabolism 45 (8 Suppl 1):115-116, 1996

25. Giustina A, Chanson P, Bronstein MD, Klibanski A, Lamberts S, Casanueva FF, et al: A consensus on criteria for cure of acromegaly. J Clin Endocrinol Metab 95:3141-3148, 2010

26. Gondim JA, Almeida JP, Albuquerque LA, Gomes EF, Schops M: Giant pituitary adenomas: surgical outcomes of 50 cases operated on by the endonasal endoscopic approach. World Neurosurg 82:e281-e290, 2014

27. Guiot J, Rougerie J, Fourestier M, Fournier A, Comoy C, Vulmiere J, et al: [Intracranial endoscopic explorations.] Presse Med 71:1225-1228, 1963 (Fr)

28. Hagiwara A, Inoue Y, Wakasa K, Haba T, Tashiro T, Miyamoto T: Comparison of growth hormone-producing and non-growth hormone-producing pituitary adenomas: imaging characteristics and pathologic correlation. Radiology 228:533-538, 2003

29. Hardy J: Transsphenoidal surgery of hypersecreting pituitary tumors, in Kohler PO, Ross GT (eds): Diagnosis and Treatment of Pituitary Tumors: Proceedings of a Conference. Amsterdam: Excerpta Medica, 1973, pp 179198

30. Hardy J, Vezina JL: Transsphenoidal neurosurgery of intracranial neoplasm. Adv Neurol 15:261-273, 1976

31. Hardy J, Wigser SM: Trans-sphenoidal surgery of pituitary fossa tumors with televised radiofluoroscopic control. J Neurosurg 23:612-619, 1965

32. Hentschel SJ, McCutcheon E, Moore W, Durity FA: P53 and MIB-1 immunohistochemistry as predictors of the clinical behavior of nonfunctioning pituitary adenomas. Can J Neurol Sci 30:215-219, 2003

33. Herman V, Drazin NZ, Gonsky R, Melmed S: Molecular screening of pituitary adenomas for gene mutations and rearrangements. J Clin Endocrinol Metab 77:50-55, 1993

34. Jankowski R, Auque J, Simon C, Marchal JC, Hepner $\mathrm{H}$, Wayoff M: Endoscopic pituitary tumor surgery. Laryngoscope 102:198-202, 1992 
35. Jefferson G: The Invasive Adenomas of the Anterior Pituitary. Liverpool: University Press, 1955

36. Jho HD: Endoscopic transsphenoidal surgery. J Neurooncol 54:187-195, 2001

37. Jho HD, Carrau RL: Endoscopic endonasal transsphenoidal surgery: experience with 50 patients. J Neurosurg 87:44-51, 1997

38. Jho HD, Carrau RL: Endoscopy assisted transsphenoidal surgery for pituitary adenoma. Technical note. Acta Neurochir (Wien) 138:1416-1425, 1996

39. Kabil MS, Eby JB, Shahinian HK: Fully endoscopic endonasal vs. transseptal transsphenoidal pituitary surgery. Minim Invasive Neurosurg 48:348-354, 2005

40. Kim MS, Jang HD, Kim OL: Surgical results of growth hormone-secreting pituitary adenoma. J Korean Neurosurg Soc 45:271-274, 2009

41. Kitano M, Taneda M, Shimono T, Nakao Y: Extended transsphenoidal approach for surgical management of pituitary adenomas invading the cavernous sinus. J Neurosurg 108:26-36, 2008

42. Knosp E, Kitz K, Perneczky A: Proliferation activity in pituitary adenomas: measurement by monoclonal antibody Ki-67. Neurosurgery 25:927-930, 1989

43. Knosp E, Kitz K, Steiner E, Matula C: Pituitary adenomas with parasellar invasion. Acta Neurochir Suppl (Wien) 53:65-71, 1991

44. Knosp E, Steiner E, Kitz K, Matula C: Pituitary adenomas with invasion of the cavernous sinus space: a magnetic resonance imaging classification compared with surgical findings. Neurosurgery 33:610-618, 1993

45. Kontogeorgos G, Kapranos N, Thodou E, Sambaziotis D, Tsagarakis S: Immunocytochemical accumulation of p53 in corticotroph adenomas: relationship with heat shock proteins and apoptosis. Pituitary 1:207-212, 1999

46. Kovacs K, Horvath E, Vidal S: Classification of pituitary adenomas. J Neurooncol 54:121-127, 2001

47. Landolt AM, Shibata T, Kleihues P: Growth rate of human pituitary adenomas. J Neurosurg 67:803-806, 1987

48. Levy A, Hall L, Yeudall WA, Lightman SL: p53 gene mutations in pituitary adenomas: rare events. Clin Endocrinol (Oxf) 41:809-814, 1994

49. Liu JK, Schmidt MH, MacDonald JD, Jensen RL, Couldwell WT: Hypophysial transposition (hypophysopexy) for radiosurgical treatment of pituitary tumors involving the cavernous sinus. Technical note. Neurosurg Focus 14(5):E11, 2003

50. Lonser RR, Ksendzovsky A, Wind JJ, Vortmeyer AO, Oldfield EH: Prospective evaluation of the characteristics and incidence of adenoma-associated dural invasion in Cushing disease. J Neurosurg 116:272-279, 2012

51. Losa M, Mortini P, Barzaghi R, Ribotto P, Terreni MR, Marzoli SB, et al: Early results of surgery in patients with nonfunctioning pituitary adenoma and analysis of the risk of tumor recurrence. J Neurosurg 108:525-532, 2008

52. Meij BP, Lopes MB, Ellegala DB, Alden TD, Laws ER Jr: The long-term significance of microscopic dural invasion in 354 patients with pituitary adenomas treated with transsphenoidal surgery. J Neurosurg 96:195-208, 2002

53. Melmed S, Casanueva FF, Hoffman AR, Kleinberg DL, Montori VM, Schlechte JA, et al: Diagnosis and treatment of hyperprolactinemia: an Endocrine Society clinical practice guideline. J Clin Endocrinol Metab 96:273-288, 2011

54. Messerer M, Dubourg J, Saint-Pierre G, Jouanneau E, Sindou M: Percutaneous biopsy of lesions in the cavernous sinus region through the foramen ovale: diagnostic accuracy and limits in 50 patients. J Neurosurg 116:390-398, 2012

55. Oliveira MC, Marroni CP, Pizarro CB, Pereira-Lima JF, Barbosa-Coutinho LM, Ferreira NP: Expression of p53 protein in pituitary adenomas. Braz J Med Biol Res 35:561565,2002
56. Pan LX, Chen ZP, Liu YS, Zhao JH: Magnetic resonance imaging and biological markers in pituitary adenomas with invasion of the cavernous sinus space. J Neurooncol 74:71-76, 2005

57. Papay FA, Benninger MS, Levine HL, Lavertu P: Transnasal transseptal endoscopic repair of sphenoidal cerebral spinal fluid fistula. Otolaryngol Head Neck Surg 101:595-597, 1989

58. Parkinson D: Surgical anatomy of the lateral sellar compartment (cavernous sinus). Clin Neurosurg 36:219-239, 1990

59. Platta CS, Mackay C, Welsh JS: Pituitary adenoma: a radiotherapeutic perspective. Am J Clin Oncol 33:408-419, 2010

60. Rudnik A, Zawadzki T, Wojtacha M, Bazowski P, Gamrot J, Galuszka-Ignasiak B, et al: Endoscopic transnasal transsphenoidal treatment of pathology of the sellar region. Minim Invasive Neurosurg 48:101-107, 2005

61. Sekhar LN, Møller AR: Operative management of tumors involving the cavernous sinus. J Neurosurg 64:879-889, 1986

62. Selman WR, Laws ER Jr, Scheithauer BW, Carpenter SM: The occurrence of dural invasion in pituitary adenomas. $\mathbf{J}$ Neurosurg 64:402-407, 1986

63. Shaw PH: The role of p53 in cell cycle regulation. Pathol Res Pract 192:669-675, 1996

64. Shou XF, Li SQ, Wang YF, Zhao Y, Jia PF, Zhou LF: Treatment of pituitary adenomas with a transsphenoidal approach. Neurosurgery 56:249-256, 2005

65. Sindou M, Chavez JM, Saint Pierre G, Jouvet A: Percutaneous biopsy of cavernous sinus tumors through the foramen ovale. Neurosurgery 40:106-111, 1997

66. Thapar K, Kovacs K, Scheithauer BW, Stefaneanu L, Horvath E, Pernicone PJ, et al: Proliferative activity and invasiveness among pituitary adenomas and carcinomas: an analysis using the MIB-1 antibody. Neurosurgery 38:99-107, 1996

67. Viera AJ, Hinderliter AL: Evaluation and management of the patient with difficult-to-control or resistant hypertension. Am Fam Physician 79:863-869, 2009

68. Widhalm G, Wolfsberger S, Preusser M, Fischer I, Woehrer A, Wunderer J, et al: Residual nonfunctioning pituitary adenomas: prognostic value of MIB-1 labeling index for tumor progression. J Neurosurg 111:563-571, 2009

69. Williams JR: The Declaration of Helsinki and public health. Bull World Health Organ 86:650-652, 2008

70. Wolfsberger S, Ba-Ssalamah A, Pinker K, Mlynárik V, Czech T, Knosp E, et al: Application of three-tesla magnetic resonance imaging for diagnosis and surgery of sellar lesions. $\mathbf{J}$ Neurosurg 100:278-286, 2004

71. Wolfsberger S, Kitz K, Wunderer J, Czech T, BoecherSchwarz HG, Hainfellner JA, et al: Multiregional sampling reveals a homogenous distribution of Ki-67 proliferation rate in pituitary adenomas. Acta Neurochir (Wien) 146:13231328,2004

72. Wolfsberger S, Wunderer J, Zachenhofer I, Czech T, BöcherSchwarz HG, Hainfellner J, et al: Expression of cell proliferation markers in pituitary adenomas-correlation and clinical relevance of MIB-1 and anti-topoisomerase-IIalpha. Acta Neurochir (Wien) 146:831-839, 2004

73. Wu ZB, Yu CJ, Su ZP, Zhuge QC, Wu JS, Zheng WM: Bromocriptine treatment of invasive giant prolactinomas involving the cavernous sinus: results of a long-term follow up. J Neurosurg 104:54-61, 2006

74. Yasuda A, Campero A, Martins C, Rhoton AL Jr, de Oliveira E, Ribas GC: Microsurgical anatomy and approaches to the cavernous sinus. Neurosurgery 56 (1 Suppl):4-27, 2005

75. Yasuda A, Campero A, Martins C, Rhoton AL Jr, de Oliveira E, Ribas GC: Microsurgical anatomy and approaches to the cavernous sinus. Neurosurgery 62 (6 Suppl 3):1240-1263, 2008

76. Yasuda A, Campero A, Martins C, Rhoton AL Jr, Ribas GC: 
The medial wall of the cavernous sinus: microsurgical anatomy. Neurosurgery 55:179-190, 2004

77. Yi W, Ohman K, Brännström T, Bergenheim AT:

Percutaneous biopsy of cavernous sinus tumour via the foramen ovale. Acta Neurochir (Wien) 151:401-407, 2009

78. Zada G, Lin N, Laws ER Jr: Patterns of extrasellar extension in growth hormone-secreting and nonfunctional pituitary macroadenomas. Neurosurg Focus 29(4):E4, 2010

\section{Author Contributions}

Conception and design: Micko. Acquisition of data: Micko. Analysis and interpretation of data: Micko, Wöhrer. Drafting the article: Micko. Critically revising the article: Knosp, Wolfsberger. Reviewed submitted version of manuscript: all authors. Approved the final version of the manuscript on behalf of all authors: Knosp. Statistical analysis: Micko. Administrative/technical/ material support: Wöhrer.

\section{Correspondence}

Engelbert Knosp, Department of Neurosurgery, Medical University of Vienna, Waehringer Guertel 18-20, 1097 Vienna, Austria.email: engelbert.knosp@meduniwien.ac.at. 